\title{
Wittgenstein e o uso da linguagem como um cálculo
}

\author{
Michel Le Du \\ Université de Strasbourg \\ m.ledu@orange.fr
}

resumo Este artigo examina o papel da analogia do cálculo na filosofia da linguagem de Wittgenstein, desde seu período intermediário até o assim chamado último período. Esse papel se transformou porque Wittgenstein se afastou de uma interpretação estrita em direção a uma interpretação frouxa dessa analogia. A analogia se torna frouxa assim que se admite que 0 uso da linguagem e o cálculo podem ser comparados de diferentes maneiras e por diferentes razões. 0 alvo comum das duas interpretações é a erradicação de um mentalismo que toma equivocadamente pensamento e compreensão como processos e estados ocorrendo na mente do falante, mas Wittgenstein foi progressivamente descobrindo que uma leitura estrita da analogia sugere uma imagem falsa da posição que as regras ocupam na linguagem.

palavras-chave modelo; Wittgenstein; cálculo; metáfora; Big Typescript; mentalismo

\section{I}

Numa conversa com Waismann em setembro de 1931, intitulada "Intention, meinen und bedeuten" (WITTGENSTEIN, 1967), Wittgenstein diz discordar de duas concepções do entendimento da linguagem. Ele rejeita tanto a concepção que assimila o entendimento a um estado interno quanto a concepção que o assimila a um processo interno ${ }^{1}$. Ele não diz, obviamente, que tais processos e estados não existem; eles de fato existem e podem ser de grande interesse para o psicólogo. Pode ser muito interessante notar que meu entendimento de uma sentença é acompanhado Recebido em 05 de maio de 2008. Aceito em 10 de outubro de 2008. Tradução: Bento Prado Neto. doispontos, Curitiba, São Carlos, vol. 6, n. 1, p.167-179, abril, 2009 
por sentimentos, associações psicológicas, Vorstellungen etc. Mas, justamente, esses fenômenos são apenas acompanhamentos daquilo que denotamos por um verbo como entender. Por vezes, Wittgenstein parece apenas estar dizendo que esses fenômenos internos não são aquilo que o interessa. Mas ele está também fazendo uma observação conceitual: verbos como verstehen ou meinen, corretamente entendidos, não podem ser usados para denotar esses fenômenos. É importante perceber o quanto as convicções de Wittgenstein permaneceram estáveis a esse respeito, desde seu período intermediário até o assim chamado último período. Em uma de suas observações sobre a filosofia da psicologia, ele faz uma observação extremamente similar acerca da conexão entre o conceito de linguagem e conceito de pensamento:

Es ist nicht war, dass Denken eine Art Sprechen ist... Der Begriff "denken" ist vom Begriff "sprechen" kategorisch verschieden. Aber natürlich ist das Denken keine Begleitung des Sprechens noch sonst irgend eines Vorgang. Dass heisst: man kann z.b. den "Denkvorgang" nicht unbegegleitet vor sich gehen lassen. (WITTGENSTEIN, 1984a, vol. 1, \$ 7$)$

O ponto, no trecho que acabamos de citar, parece consistir em que, se entender uma sentença fosse, de um modo ou de outro, um processo paralelo à própria sentença, poder-se-ia apreender esse processo desacompanhado, através da introspecção ${ }^{2}$. Mas tal não é o caso. $\mathrm{O}$ pensamento não tem divisões como aquelas que se pode encontrar em outras atividades como falar, por exemplo. É por isso que a única conclusão é (1) que o pensamento (ou compreensão) é categorialmente diferente de conceitos como falar ou ler e (2) que se subestima a diferença entre esses conceitos (i.e. o fato de que essa diferença é categorial) tão logo se considera a compreensão, por exemplo, como um processo autônomo que mantém relações contingentes e empíricas com outro processo (= fala).

$\mathrm{Na}$ discussão com Waismann que evocamos há pouco, Wittgenstein critica, de um lado, uma concepção mentalista daquilo em que consiste para uma sentença significar algo e, de outro, ressalta que "Ich verstehe den Satz, indem ich ihn anwende... der Satz ist dazu da, dass wir mit ihm operieren." A conexão estabelecida por Wittgenstein entre a compreen- 
são da linguagem e um cálculo deve ser entendida sob o pano de fundo de suas tendências anti-mentalistas. É por isso que lhe ocorre dizer que "Das Verstehen eines Wortes oder eines Satz ist ein Kalkulieren" (ibid.) Não é realmente difícil de entender como a analogia do cálculo pode ser utilizada de modo a sustentar uma concepção anti-mentalista: em um cálculo, nós procedemos passo a passo e o processo inteiro pode ser realizado publicamente 3 . O problema é que, na época de suas conversas com o Círculo de Viena, Wittgenstein diz explicitamente que essa analogia é na verdade mais do que uma simples analogia, como se pode ver no seguinte trecho:

Es besteht nämlich zwischen der Art der Verwendung unserer Worte in der Sprache und einem Kalkül nicht etwa eine blosse Analogie, sondern ich kann tatsächlich den Begriff des Kalküls so fassen, dass die Anwendung der Worte darunter fällt. (WITTGENSTEIN, 1967, ibid., grifo meu)

Para entender esse trecho, devemos ter em mente que a palavra "analogia" expressa um conceito de contornos esfumados. Algumas analogias baseiam-se em traços bastante superficiais e outras em semelhanças estruturais mais profundas entre os objetos. Assim, a coisa lógica a se fazer parece ser distinguir entre analogia num sentido fraco e analogia num sentido mais forte. Se nos voltarmos para o sentido fraco, provavelmente nos sentiremos inclinados a dizer que há "mais do que uma analogia" entre os números naturais racionais e reais, por exemplo. Mas, à luz do que o último Wittgenstein diz, pode-se, ao mesmo tempo, (1) defender a idéia de que analogias não existem apenas entre entidades que caem sob conceitos diferentes, mas também entre entidades conectadas a ramos distintos do mesmíssimo conceito analógico e (2) dizer que o conceito de cálculo é um tal conceito analógico (exatamente como "número", "regra", "proposição" etc.). Tomando as coisas desse modo, pode-se avançar a seguinte interpretação para mais do que uma simples analogia: o que na verdade se visa por meio dessa frase é que, ao construir o conceito de cálculo de modo a fazê-lo recobrir o uso da linguagem, acrescentamos um novo ramo a um conceito analógico.

Duas objeções podem ser levantadas contra a argumentação anterior. Primeiro, pode-se objetar que se faz aqui um uso retrospectivo da noção 
de semelhança de família, uma noção que se costuma pensar ser característica do último período de Wittgenstein, o que seria criticável. Outra objeção consistiria em dizer que, dentro de um conceito, as conexões entre os diferentes ramos são freqüentemente muito frouxas e, conseqüentemente, as analogias entre objetos que caem sob o mesmo conceito analógico nem sempre são mais fortes do que as outras. Acerca da primeira objeção, o melhor modo de respondê-la consiste em lembrar que mesmo se a expressão semelhança de família se tornou central apenas mais tarde na filosofia de Wittgenstein, sua primeiríssima ocorrência encontra-se no Big Typescript e a idéia é claramente recorrente na Philosophische Grammatik, onde são largamente antecipadas as famosas observações de Wittgenstein acerca do conceito de jogo nas Philosophische Untersuchungen, como se pode ver no seguinte trecho:

So gibt es wohl nicht ein Charakteristicum, das allem was wir Spiel nennen gemeinsam ist. Aber man kann auch nicht sagen, "Spiel” habe eben mehrere unabhängige Bedeutungen (etwa wie das Wort "Bank"). "Spiele" nennt man vielmehr auf verschiedene Weisen mit einander verwandte Vorgänge, zwischen denen es eine Mannigfaltigkeit von Übergangen gibt. (WITTGENSTEIN, 1984b, II, \ 35)

Desse modo, Wittgenstein pode perfeitamente ter concebido a noção de semelhança de família antes de usar regularmente a expressão. Acrescente-se a isso que a própria idéia de Familieahnlichkeiten se encontra prenunciada na comparação de Jean Nicod entre diferentes tipos de semelhança (NICOD, 1924) e no modo pelo qual Nietzsche lida com conceitos filosóficos (NIETZSCHE, 1999, \20), e temos boas razões para pensar que Wittgenstein tinha conhecimento desses textos. Assim, a verdadeira dificuldade dá-se com a segunda objeção. Wittgenstein de fato diz, em sua conversa com Waismann, que nosso conceito de cálculo pode ser concebido de modo que possa incluir o uso da linguagem, mas é verdade (como o trecho da Philosophische Grammatik que citamos acima sugere) que conexões entre diferentes ramos de um conceito analógico podem ser muito frouxas e, assim, a possibilidade de tal extensão não prova que temos aqui mais do que uma mera (= frouxa) analogia entre ambos. Portanto, se Wittgenstein pensa que o uso da linguagem é, estritamente falando, uma variedade de cálculo, como ele aparentemente pensa 
em novembro de 1930, isso não pode se dar simplesmente com base na idéia de que o conceito de cálculo não tem fronteiras fixas e pode até certo ponto ser estendido: isso deve se dar porque ele admite que tanto aquilo que todo mundo chama de cálculo quanto o uso de conceitos são governados por um sistema de regras.

Em sua última filosofia, Wittgenstein martela essa concepção e procura mostrar que ela não se aplica nem mesmo a nomes próprios (WIITGENSTEIN, 1984c, \ 79; e FOGELIN, 1987, p. 134 para um comentário). Se o papel das regras no uso da linguagem mostra-se diferente do papel das regras no cálculo, então a analogia entre os dois só pode ser uma analogia frouxa: há possivelmente muitos meios, e não um só, de comparar o uso da linguagem com um cálculo, e, como diz Wittgenstein na Philosophische Grammatik, a analogia entre os dois é mais bem usada quando refletimos não sobre o uso dos sinais e das sentenças, mas sobre o seu sentido (o sentido sendo identificado com aquilo que responde a pergunta pela explicação do sentido), seu pensamento etc. É o que é claramente enunciado na Philosophische Grammatik:

Ich sagte, es sei das System der Sprache, welches den Satz zum Gedanken macht und ihn uns zum Gedanken macht. Es heisst nicht: es ist das System der Sprache, welches uns den Satz, wenn wir ihn gebrauchen, zum Gedanken macht, denn das System ist dann nicht anwesend und es braucht gar nichts, das uns den Satz lebendig macht, da die Frage der Lebendigkeit gar nicht auftaucht. Wenn wir dagegen fragen: "warum kommt uns der Satz nicht isoliert und tot vor, wenn wir nämlich über sein Wesen, seinen Sinn, den Gedanken, etc. nachdenken", so kann man sagen dass wir uns dann im System der Sprache weiterbewegen. (WITTGENSTEIN, 1984b,VII, 104)

Na Philosophische Grammatik, Wittgenstein insiste em que o cálculo não é algo que ocorre quando alguém fala e não pertence à categoria dos Elebnisses. Ele é mais próximo de um Hintergrund de que a proposição carece para ter sentido (WITTGENSTEIN, 1984b, I, \ $\mathbb{S} 11)^{4}$. É por isso que ele acaba dizendo que a questão acerca do "cálculo" ou "sistema" de linguagem não surge enquanto se trata apenas do uso dos sinais e não de sua explicação. Sob vários aspectos, ele parece ir de um uso estrito da analogia para um mais frouxo: na Philosophische Grammatik, podemos ver 
Wittgenstein tornando-se consciente de que a comparação entre o uso da linguagem e o cálculo é, de um lado, útil no que diz respeito ao esforço filosófico de esclarecer confusões e mal-entendidos, e, de outro, unilateral. A verdade é que, na maioria das vezes, tornar explícitas as regras que governam o uso normal da linguagem é algo inteiramente diferente de descrever um cálculo feito por meio de palavras (BOUVERESSE, 1977, p. 243-246). O restante deste artigo irá se consagrar a um exame detalhado do modelo da linguagem como cálculo na filosofia de Wittgenstein segundo as linhas que acabamos de esboçar. A idéia geral é que o anti-mentalismo é base perene da conexão, mas que a analogia foi usada, após um determinado tempo, de um modo mais frouxo. Como veremos, quando essa conexão é mal compreendida, ela muito freqüentemente se torna um cavalo de Tróia mentalista, que sugere que o cálculo é uma metáfora apropriada para os assim chamados "processos de pensamento".

\section{II}

Uma crítica pormenorizada da idéia da linguagem como um sistema baseado em regras estritas é desenvolvido por Wittgenstein no Blue Book. A base dessa crítica é a idéia de que, na maioria das vezes, não pensamos em tais regras quando usamos nossa linguagem e sequer somos capazes de fornecê-las quando questionados porque muitos de nossos conceitos não são claramente delimitados. Essa é a primeira razão pela qual o assim chamado modelo do cálculo parece ser tão unilateral. Wittgenstein também nota que por vezes o comportamento não envolve a regra: a regra tornou-se uma segunda natureza e o agente não precisa fazer nada para aplicá-la. É tipicamente o que acontece com as regras de xadrez quando alguém se torna um exímio enxadrista, por exemplo: ele já não se sente inclinado a justificar suas próprias ações mencionando as regras do xadrez porque elas se tornaram óbvias demais para serem mencionadas como razões para aquilo que ele faz (WITTGENSTEIN, 1958, p. 13). Pode-se dizer que o mesmo acontece com a aritmética básica: o comportamento de uma pessoa realmente exímia em calcular não envolve as regras da aritmética, mas isso parece invalidar antes o "modelo de consulta à regra" do 
que o modelo do cálculo enquanto tal. Desse modo, o verdadeiro problema com este último modelo parece consistir em que ele fornece uma imagem muito restritiva do uso da linguagem. Uma ação (um ato de fala, por exemplo) não pode ser simplesmente o cumprimento da regra, mesmo se esse cumprimento é pensado como algo puramente instintivo e que não envolve um ato mental. Como Wittgenstein diz às vezes, uma prática não pode nunca ser inteiramente determinada por uma regra: além de um certo ponto, a prática "fala por si mesma".

Além disso, "unilateral" não significa "irrelevante" ou "sem utilidade". De um determinado ponto de vista, pode-se dizer que todo modelo implica alguma distorção da realidade. A unilateralidade torna-se uma fonte de problemas assim que a distorção é esquecida e modelo é visto como uma imagem realística do domínio de objetos de que trata. Quando um economista descreve o comportamento de um agente puramente racional, cuja única motivação é seu interesse (i.e.: o aumento de seu salário e proventos) e apenas aplica regras estritas de comportamento econômico, ele normalmente sabe que ele está lidando com um objeto abstrato e não o equivoca por um objeto concreto. Portanto, na verdade a questão diz respeito à nossa propensão a interpretar o modelo de um modo realístico: quer imaginemos que nossa linguagem é uma aproximação grosseira de um cálculo de regras estritas (exatamente como o movimento concreto de um corpo se aproxima da queda no vácuo) quer se postule um idioma de pensamento oculto estritamente governado por regras, ao passo que a linguagem corrente não o é; e é aqui que o indesejado mentalismo entra novamente em cena (WITTGENSTEIN, 1984b, \$100).

Agora, se prosseguimos na comparação com a ciência econômica, devemos notar que regiões da realidade são mais bem descritas por um determinado modelo abstrato do que outras. O modelo do agente racional que aplica regras econômicas estritas se adéqua melhor ao comportamento de um investidor na City of London do que ao de um monge em alguma comunidade isolada que dedicou sua vida a Deus. A razão disso é que, em nossas sociedades, a vida econômica tornou-se, até certo ponto, autônoma (é o que John Stuart Mill já dizia cento e cinqüenta anos atrás). Será que podemos dizer: o modelo do cálculo se adéqua melhor a certas áreas da linguagem do que a outras? Se tomamos como exemplo uma sentença como "João aprecia mulheres e homens de 
idade avançada" 5 o modelo pode parecer plausível. A sentença pode receber duas interpretações diferentes, de acordo com o modo pelo qual seu sentido é calculado com base no sentido de seus termos. Podemos entender que (1) João aprecia mulheres e (homens velhos) ou (2) João aprecia (mulheres e homens velhos). Mas o modelo não tem aplicação clara no caso de uma sentença como "He didn't want to spend another year beeing Doctor No"6. Aqui, é impossível ver o sentido da sentença no seu todo como uma computação do sentido de seus sinais (o humor ou a ironia de uma sentença não é uma composição do humor ou da ironia de suas partes). O sentido, aqui, é contextual: precisamos entender que X é um antigo membro da comissão de censura e não quer prosseguir com esse trabalho por mais um ano. Assim, como diz Bruce Goldberg, se o ouvinte não sabe que a proposição anterior era "Sullivan decidiu renunciar da comissão de censura", a sentença é ininteligível, independentemente de qualquer computação que se possa fazer com os signos.

\section{III}

Como dissemos, o mentalismo que Wittgenstein procura combater vem na esteira do modelo de cálculo assim que esse modelo é interpretado de modo realístico. É provavelmente o que Jacques Bouveresse tinha em mente quando ele escreveu:

En d'autres termes, si la métaphore du calcul jette une lueur essentielle sur ce qu'on appelle, au niveau de la description linguistique, "le sens" et l'“explication du sens", notamment en écartant certaines représentations inadéquates, elle ne nous éclaire pas du tout sur ce qui se passe lorsque nous appliquons le calcul, lorsque nous utilisons les signes et elle peut même nous en donner une explication tout à fait trompeuse (BOUVERESSE 1977, p. 321).

Isso sugere que o único campo em que a analogia entre linguagem e cálculo é mais do que uma analogia frouxa é o campo da "explicação de sentido”, em contraposição ao do uso espontâneo. Quando um falante "explica" ou "interpreta" o sentido, ele faz algo, ele está engajado em algo que requer passos a serem dados, exatamente como quando alguém reali- 
za uma operação aritmética ${ }^{7}$. Na maioria das vezes, nosso entendimento da frase que escutamos ou proferimos é instintivo e não precisamos seguir um protocolo para consegui-lo: tal protocolo existe quando uma interpretação se faz necessária, e uma interpretação é algo que o falante faz (eine Tatigkeit), algo que ele pode fazer publicamente, exatamente como ocorre com o calcular ${ }^{8}$. Como diz Wittgenstein “... Tun ist etwa man Einem vormacht”. Desse modo, se a compreensão não é, normalmente, algo que nós fazemos, e se com relação a um cálculo, pelo contrário, se supõe justamente que ele seja feito, então o modelo do cálculo se revela uma ficção (isto é, um modelo "como se"). Tal modelo, corretamente compreendido, é apenas um artificio para unificar os dados comportamentais. Se eu modelizar meu sistema nervoso como um tanque com determinada quantidade de líquido dentro, como aparentemente Konrad Lorenz fez algures, a virtude cognitiva de tal modelo está em sua capacidade de estabelecer correlações entre respostas e estímulos comportamentais muito diferentes: a força da resposta diminui após certo tempo se o sujeito foi repetidamente estimulado (o tanque está se esvaziando) e é por vezes possível obter uma resposta sem qualquer estímulo (o tanque transborda). Quanto maior for o número de fatos que tal modelo permite abarcar, tanto mais ele será levado a sério. Mas um cientista normal não irá se queixar de que não temos nenhuma evidência acerca da água ou do tanque (McINTYRE, 1958, cap. 2).Vimos sucessivamente os modelos (1) como implicando uma espécie de unilateralidade ou distorção e (2) como sendo, num certo sentido, ficções. O pensador que toma por seu valor de face o modelo do cálculo se coloca numa situação muito semelhante à do cientista estranho que procura por evidências do tanque e da água, e se mostra mal-avisado quando imagina processos autônomos guiados por regras na mente, processos que corresponderiam àquilo que chamamos compreender ou pensar.

As coisas seriam inteiramente diferentes se o modelo tanque-e-água fosse como o modelo hidrodinâmico na eletricidade. No caso desse último modelo, ninguém deve esperar que as partículas elétricas venham a cair no chão quando o fio for cortado, como a água verte quando a mangueira do quintal é furada, mas é perfeitamente correto descrever metaforicamente o que está ocorrendo neste mesmíssimo fio como um fluxo de partículas. Uma metáfora como aquela inspirada na analogia 
hidrodinâmica com a eletricidade pode também ser chamada de metáfora geradora de um modelo. Tal metáfora suscita novas hipóteses e experimentos. Tem também implicações ontológicas que os modelos do tipo anterior não tinham. Uma metáfora diz que A é como e não é como B ao mesmo tempo: a corrente elétrica é como a corrente de água (é feita de partículas que se movem rapidamente) e dessemelhante ao mesmo tempo (ele não flui para fora do conector como a água). Muitos filósofos sustentariam que o modelo do cálculo é como o modelo hidrodinâmico (e não como o modelo água-e-tanque): eles pensam que compreender, raciocinar, pensar, são processos na mente que se parecem, e ao mesmo tempo não se parecem, com a atividade de calcular publicamente, passo a passo. Pensam que não se parecem porque o cálculo é feito com a ajuda de sinais convencionais numa folha de papel, ao passo que o pensamento e a compreensão supostamente exigem um idioma diferente, em outras palavras: símbolos mentais na mente. É o que a doutrina clássica de Hobbes afirma no Leviathan, i. e. a distinção entre o discurso verbal e o mental; tal é também a concepção de filósofos da mente contemporâneo, como Fodor, que se inclinam pela hipótese de uma linguagem mental, o assim chamado mentalês ${ }^{9}$.É por isso que acreditam que o computador seja a melhor metáfora para a mente.

\section{IV}

É surpreendente ver o quanto o modelo do cálculo, assim que seu escopo é mal detectado, nos arrasta para uma concepção mecanicista da mente, estranha, sob todos os aspectos, ao modo pelo qual Wittgenstein filosofa. A confusão que subjaz a tal concepção está profundamente enraizada numa má compreensão acerca do que deve ser um modelo para a mente. Se uma regra for entendida como uma efetividade, canalizando processos na mente, então a regra é tomada equivocadamente por um mecanismo e isso é provavelmente uma das maiores fontes de confusão nas ciências contemporâneas da mente, bem como na antropologia e na lingüística.

Ao longo deste texto, vimos que uma analogia forte entre linguagem e cálculo só se mostrava relevante no que dizia respeito à interpretação e à explicação. Exatamente como um cálculo, uma interpretação faz-se por 
passos e leva a um resultado.Vimos que, tomado como uma descrição do uso espontâneo da linguagem, o modelo do cálculo era ao mesmo tempo unilateral e ficcional. $\mathrm{O}$ fato de que Wittgenstein, em determinado momento de seu percurso, sentiu-se atraído por uma interpretação forte da analogia do cálculo e, posteriormente, enfraqueceu consideravelmente sua interpretação nos sugere uma medida profilática para evitar as confusões conceituais anteriores: não pense o conceito de regras, em particular, e os conceitos intencionais em geral, como denotando efetividades; na medida em que esses conceitos estiverem em pauta, liberte-se do mito de algo ocorrendo na mente.

1 "Ich glaube nun, dass das Verstehen gar kein besonderer Prozess ist, der noch ausserdem da ist und zu der Wahrnehmung des Satzbildes hinzukommt. (...) Die Ansicht gegen die ich mich in diesem Zusammenhang kehren möchte, ist die, dass es sich bei dem Verstehen um einem Zustand handelt, der in mir vorhanden ist, wie, z. B. die Zahnschmerzen." (WITTGENSTEIN, 1967, Conversation with Waismann, September the 21st, 1931)

${ }^{2}$ Ver também WITTGENSTEIN, 1984a, vol. 1, \580: "DerVergleich des Denkens mit einem Vorgang in der Verborgenheit ist, in der Philosophie, irreführend."

3 “Ich kann Ihnen nähmlich sagen: "Holen Sie das Benzin!" Und durch diese Aufschrift ist eine Regel da, nach der Sie vorgehen können. Wenn Sie das Benzin holen, so ist das wieder ein Schritt in demjenigen Kalkül der durch die Regeln bestimmt ist. Ich nenne das ganze einen Kalkül, weil jetzt zwei Möglichkeiten bestehen, nämlich dass Sie nach der Regel vorgehen oder dass sie nicht nach der Regel vergehen." (WITTGENSTEIN, 1967, ibid., grifo meu).

4 A esse respeito, é interessante notar que Wittgenstein usa o mesmo exemplo (o nome próprio "Napoleão") em sua conversa com Waismann e na Philosophische Grammatik de dois modos ligeiramente distintos. Em sua resposta a Waismann, ele insiste no fato de que está consciente do sentido do nome do mesmo modo pelo qual está consciente de que $2+2=$ 4. Em outras palavras, a compreensão do sentido é uma disposição e, assim sendo, não se pode atribuir um sentido claro à questão "Em que momento determinado você entendeu a palavra?”. Na Philosophische Grammatik a questão parece ser a de que responder a uma questão acerca do sentido em que um nome próprio deve ser tomado é efetuar um novo passo no cálculo. "Die Antwort 'ich habe den Sieger von Austerlitz gemient' ist ein neuer Schritt in unsern Kalkül.” (WITTGENSTEIN, 1984b,V, \$ 63).

5 O exemplo foi tomado de FODOR, 1968, cap. 6.

${ }^{6}$ Ver GOLDBERG, 1991.

7 Num trecho de seus cursos em Cambridge, Wittgenstein diz que uma palavra como compreender pode ser tomada quer como (a) algo que ocorre na mente na qualidade de um 
evento consciente (b) uma disposição (c) uma tradução (WITTGENSTEIN, 1979, p. 113). O primeiro uso parece denotar as típicas experiências de insight (ou Einsicht) ; o segundo remete à compreensão irrefletida e instintiva que temos de palavras e sentenças comuns; o terceiro corresponde aos casos em que o falante explica suas próprias palavras para um ouvinte e, ao assim fazer, traduz suas próprias sentenças. Isto é tipicamente o que Wittgenstein entende por interpretação: uma interpretação é, para ele, sempre uma tradução.

8 WITTGENSTEIN, 1984a, vol.1, \651-655. Nesses parágrafos, Wittgenstein sugere que calcular é normalmente descrito como uma Tatigkeit, mas pode também ser descrito como ein Können (pense na situação em que alguém abaixa a cabeça e encontra o resultado do cálculo sem seguir o protocolo). No último caso, o cálculo pode ser descrito como não envolvendo a regra.

${ }^{9}$ Cf. FODOR, 1975 e, para uma discussão crítica, HACKER, 1987. A noção de metáforas geradoras de modelos foi extraída de Hacker. Também me inspirei no célebre artigo de Max Black, "Metaphor" (BLACK, 1962).Ver também HAUGELAND, 1985. Centenas de livros e artigos foram escritos acerca dessas idéias; damos aqui apenas algumas poucas referências.

\section{Referências bibliográficas}

BLACK, M. 1962. "Metaphor" in Models and metaphors, Cornell, Ithaca, p. 25-47.

BOUVERESSE, J. 1977. Le mythe de l'intériorité, Paris, Minuit.

FODOR, J. 1968. Psychological explanation, Random House, New-York. ,1975. The language of thought, Harvard UP, Cambridge.

FOGELIN, R. 1987. Wittgenstein, Routledge, London.

GOLDBERG, B. 1991. "Mechanism and meaning” in Investigating

Wittgenstein, John Hyman (ed.), Routledge, London, p. 48-66.

HACKER, P. 1987. "Languages, minds and brains" in Mindwaves, Colin Blakemore and Susan Greenfield (eds), Blackwell, Oxford, p. 485-506

HAUGELAND, J. 1985. Artificial intelligence, the very idea, MIT Press, Cambridge.

McINTYRE, A. 1958. The unconscious, Routledge, London.

NICOD, J. 1924. La logique dans le monde sensible, Alcan, Paris. 
NIETZSCHE, F. 1999. Jenseits von Gut und Böse, Insel Verlag, Frankfurt. WITTGENSTEIN, L. 1958. The blue book and the brown book, Blackwell, London. 1967. Wittgenstein and theVienna Circle, German / English edition, Blackwell, Oxford. , 1979. Wittgenstein's lectures, Cambridge 32-35, Blackwell, London. , 1984a. Bemerkungen über die Philosophie der Psychologie, Band 1 \& 2, Suhrkamp, Frankfurt. ,1984b. Philosophische Grammatik, Suhrkamp, Frankfurt. ,1984c. Philosophische Untersuchungen, Suhrkamp, Frankfurt , 2005. The Big Typescript, Blackwell, Oxford. 